\title{
O ACORDO CONTINENTAL AFRICANO DE LIVRE COMÉRCIO: ESPERANÇAS E DESAFIOS
}

\author{
Conrado Ottoboni BAGGIO ${ }^{1}$
}

RESUMO: A assinatura do Acordo Continental Africano de Livre-Comércio (AfCFTA), em 2018, pode ser considerado um feito histórico tanto pela quantidade de países participantes quanto pelo número de pessoas e recursos abrangidos por ele. No entanto, problemas históricos referentes ao continente africano como um todo, somado às questóes internas dos países membros e a própria magnitude do acordo, trazem desafios consideráveis ao seu cumprimento efetivo. Assim, o objetivo deste artigo é apresentar o processo de criação do AfCFTA, bem como apontar os diversos obstáculos políticos e econômicos que podem afetar negativamente a sua implementação.

PALAVRAS-CHAVE: África. AfCFTA. Regionalismo.

\section{THE AFRICAN CONTINENTAL FREE TRADE AGREEMENT: HOPES AND CHALLENGES}

ABSTRACT: The signing of the Continental African Free Trade Agreement (AfCFTA), in 2018, can be considered a historic feat both in terms of the number of participating countries and the number of people and resources covered by it. However, historical problems regarding the African continent as a whole, added to the internal issues of member countries and the very magnitude of the agreement, pose considerable challenges to its effective compliance. Thus, the purpose of this article is to present the process of creating the AFCFTA, as well as to point out the various political and economic obstacles that can negatively affect its implementation.

KEYWORDS: Africa. AfCFTA. Regionalism.

\footnotetext{
1 Universidade de São Paulo (USP), Instituto de Relações Internacionais, São Paulo - SP - Brasil. Doutorando em Relações Internacionais. ORCID: 0000-0003-2330-4405. cobaggio@usp.br.
} 


\section{Introdução}

Os últimos dez anos não têm se mostrado propícios para os projetos de integração regional. Na América do Sul, o Mercosul permanece estagnado por dificuldades econômicas e desacordos ideológicos e políticos. No Sudeste Asiático, a ASEAN está lidando com diversas disparidades econômicas e disputas territoriais. Mesmo a União Europeia - vista como o modelo de integração econômica mais bem-sucedido - teve o seu futuro posto em dúvida após o processo do Brexit e a saída do Reino Unido do bloco.

Apesar desse contexto internacional desfavorável, o continente africano demonstrou recentemente que parece estar caminhando na direção contrária do resto do mundo. Em março de 2018, os países da África se reuniram para a assinatura do maior acordo comercial da história desde a criação da Organização Mundial do Comércio, em 1995: o Acordo Continental Africano de LivreComércio (AfCFTA, na sigla em inglês).

$\mathrm{O}$ acordo representou um marco na história da África. Apenas dois anos depois, em 2020, o AfCFTA já contava com a participação de 54 dos 55 países membros da União Africana (UA), contabilizando um PIB de US\$3,4 trilhôes e abarcando 1.3 bilhão de pessoas. Nos próximos anos, se for implementado plenamente, as reduçóes tarifárias previstas pelo acordo teriam o potencial de aumentar a renda dos africanos e retirar milhóes de indivíduos da pobreza extrema, além de gerar empregos e diminuir a desigualdade de gênero no continente.

Além dos seus benefícios econômicos, o AfCFTA também possui um mérito político. Durante décadas, o Pan-africanismo - a proposta de unir os povos de origem africana ao redor do mundo, com o objetivo de combater o racismo e torná-los mais fortes contra a dominação política e econômica - foi uma das ideologias mais influentes do continente, especialmente após os processos de independência. ${ }^{2}$ Nesse sentido, um acordo como o AfCFTA também representa um passo adiante para os adeptos do Pan-africanismo e a crença de que a união pode ser uma estratégia eficaz contra a competição econômica e a interferência de potências estrangeiras.

No entanto, o próprio contexto africano ainda impóe uma série de obstáculos para o processo de implementação do AfCFTA. A África possui algumas

\footnotetext{
2 Apesar de possuir vertentes e definições diferentes, de forma abrangente, o Pan-africanismo pode ser entendido como a defesa da integração internacional em prol da união econômica, política e social dos diferentes povos de origem africana ao redor do mundo. O movimento surgiu nas duas primeiras décadas do século XX, a partir das ideias de diversos intelectuais e ativistas afro-americanos e afro-caribenhos, como o norte-americano, W. E. B. Du Bois, George Padmore, de Trinidad e Tobago e o jamaicano Marcus Garvey (MARTIN, 2012).
} 
das economias com a maior taxa de crescimento do planeta - quatro dos cinco países que mais crescem no mundo são africanos - mas diversos casos de extremismo político, guerras civis, golpes de Estado, pobreza extrema e corrupção persistem em muitos países e prejudicam a estabilidade e desenvolvimento do continente. $^{3}$

Assim, o objetivo deste artigo é apresentar o Acordo de Livre-Comércio Continental Africano (AfCFTA), bem como apontar os diversos fatores políticos e econômicos que podem prejudicar a sua efetividade. Defende-se aqui a ideia de que, apesar da criação da AfCFTA por si só representar um grande marco no processo de integração africano, o continente ainda possui instabilidades políticas e econômicas que podem comprometer a implementação do acordo, em um cenário a curto e médio prazo.

Em um primeiro momento será feita uma breve apresentação dos termos e conceitos referentes ao tema amplo do Regionalismo e quais definiçóes serão aplicadas para o caso apresentado. Em seguida será apresentado um histórico do pensamento a respeito da integração do continente africano, com destaque para o papel do Pan-africanismo nesse processo. Depois, será observado o atual contexto continental africano, assim como as negociaçóes que levaram à criação do AfCFTA. Por fim, analisaremos algumas das dificuldades envolvidas na implementação do acordo.

\section{Teoria do Regionalismo e o caso da AFCFTA}

Antes de prosseguir com a descrição do processo de integração africana representado pelo AfCFTA, é necessária uma breve descrição do que "regionalismo" significa e como ele se aplica ao caso apresentado neste artigo.

Os estudos sobre Integração Regional ou Regionalismo desenvolveram-se dentro do contexto do processo de integração do continente europeu, a partir da criação da Comunidade Europeia do Carvão e do Aço em 1952, e ganhou ímpeto dentro da comunidade acadêmica durante as décadas de 1960 e 1970. Partindo da Teoria Funcionalista de David Mitrany, o tema foi subsequentemente abordado por outros autores como Ernst Haas e Joseph Nye, adquirindo diversas vertentes, cada uma com suas próprias variáveis e objetivos e, inclusive, sendo objeto de análise de diversas disciplinas e tornando difícil a adoção de uma só definição.

\footnotetext{
3 De acordo com o FMI, os quatro países que mais cresceram em 2019, foram: Sudão do Sul (11,3\%), Ruanda (10,1\%), Líbia (9,9\%) e Etiópia (9,0\%) (FUNDO MONETÁRIO INTERNACIONAL, 2019).
} 
Por essa razão, tendo em vista o grande volume de debates sobre o tema, uma definição ampla, como a apresentada por Andrew Hurrel, parece ser a mais didática e correta. Para o autor (HURREL, 1995, p.333, tradução nossa):

Regionalismo era comumente analisado em termos de coesão social (etnicidade, raça, idioma, religião, cultura, história, consciência de uma herança comum), coesão econômica (padrôes de comércio, complementaridade econômica), coesão política (tipo de regime, ideologia) e coesão organizacional (existência de instituições regionais formais). ${ }^{4}$

Uma dessas vertentes é a Teoria Intergovernamentalista. Criada por Stanley Hoffman ainda na década de 1960, a corrente Intergovernamentalista foi posteriormente desenvolvida por Andrew Moravcsik (1998) e atribui o protagonismo dos processos de integração aos governos e Estados envolvidos enquanto relega a relevância de uma possível autoridade supranacional, caso ela exista, a de um mero reforço de decisóes previamente estabelecidas.

Esse pensamento se aplica ao atual cenário africano referente ao AfCFTA. Embora muitas das discussóes e negociaçóes tenham sido feitas dentro dos encontros da União Africana, as decisóes a respeito da adesão ou não ao acordo foram tomadas exclusivamente pelos governos dos Estados envolvidos.

Outro tema debatido dentro da área de Integração Regional diz respeito às suas causas e consequências. Uma vez que grande parte dos trabalhos a respeito do tema são formulados por economistas, diversos autores tendem a considerar fatores econômicos como incentivadores dos processos de integração regional. No entanto, pesquisadores como Edward Mansfield e Etel Solingen (2010) ressaltam o caráter político por trás das iniciativas de integração.

Nesse caso, ainda que o AfCFTA seja um acordo de livre-comércio, a sua proposição, assim como a de diversas outras iniciativas de integração africanas, devem ser analisadas levando em consideração o histórico de movimentos políticos no continente, como o Pan-africanismo e o desejo de se construir uma África mais unida diante dos desafios impostos pelo legado colonial e a competiçáo do restante do mundo.

Por fim, é necessário fazer uma distinção clara entre "Regionalismo" e "Regionalização". Para John Ravenhill (2016), "Regionalismo" descreve uma

\footnotetext{
4 "Regionalism was often analyzed in terms of social cohesiveness (ethnicity, race, language, religion, culture, history, consciousness of a common heritage), economic cohesive ness (trade patterns, economic complementarity), political cohesiveness (regime type, ideology) and organizational cohesiveness (existence of formal regional institutions)" (HURREL, 1995, p.333).
} 
colaboração intergovernamental direta, dentro de uma escala geográfica restrita, em assuntos específicos, como é o caso das negociaçôes que levaram ao AfCFTA. Já a "Regionalização" refere-se a processos conduzidos por atores não estatais, que podem eventualmente optar por colaborarem em uma determinada área.

\section{A Construção do Ideal de Integração Regional no Continente Africano}

Apesar de diversas iniciativas frustradas ao longo das décadas, a ideia de integração regional no continente africano esteve presente desde o período da dominaçáo colonial europeia, inclusive com algumas das estruturas criadas na época desempenhando um papel no atual processo de integração e podendo ser encontradas até os dias de hoje.

O império português, por exemplo, já possuía o sonho de unir por terra suas colônias na África, criando uma grande "faixa cor de rosa" ligando por terra o oceano Atlântico ao Índico. Posteriormente, a expansão das ambiçôes coloniais portuguesas foi contida pelos interesses britânicos na regiáo e seus próprios projetos de integraçáo, como o desejo de construir uma ferrovia ligando as extremidades norte e sul do continente, da Cidade do Cabo, na África do Sul, ao Cairo, no Egito (MOREIRA, 1947).

Outro exemplo mais discreto, porém, mais duradouro do legado colonial nos processos de integração da África, é a União Aduaneira da Âfrica Austral (UAAA). Considerada a uniáo aduaneira mais antiga do mundo, a UAAA foi criada pelos britânicos, em 1910, e possui suas origens na integração entre as províncias do Cabo e do Estado Livre de Orange, em 1889. Posteriormente, a União passou a incluir os demais territórios da União Sul-Africana (atual África do Sul), a Basutolândia (Lesoto), Suazilândia (reino de Essuatíni), Bechunalândia (Botswana) e atualmente, a Namíbia (SACU, 2020). De forma similar, a atual Comunidade da África Oriental, criada em 1967, é resultado da União Aduaneira da África Oriental de 1922 e, segundo as palavras de um de seus secretários gerais: "[...] extraiu liçōes significativas dessas estruturas coloniais" (MWAPACHU, 2010, p.10, tradução nossa). ${ }^{5}$

No caso das antigas possessōes francesas na África Ocidental e Central, a influência das estruturas coloniais se mostra ainda mais presente. $O$ franco CFA - moeda imposta pela França às suas colônias africanas desde 1945 e atrelada ao franco (posteriormente ao euro) - foi mantido mesmo após o período das independências dos países da regiáo. No caso da União Econômica

\footnotetext{
5 “[...] drew significant lessons from these colonial structures." (MWAPACHU, 2010, p.10).
} 
e Monetária do Oeste Africano (UEMOA), o franco CFA só foi substituído em maio de 2020, enquanto a Comunidade Econômica e Monetária da África Central (CEMAC) continua a adotar a moeda.

Se antes as iniciativas de integração dos europeus na África visavam otimizar o escoamento da produção dos territórios dominados pelos impérios coloniais europeus - do interior para os portos e dali para o restante do mundo, seguindo uma lógica extrativista do domínio colonial - a partir do início dos anos 1960, com a aceleração dos processos de independência, a ideia de integração africana tornou-se um atrativo para os próprios líderes do continente.

O desejo de uma África unida passou a ser visto como uma estratégia para lidar com muitas das desvantagens do continente. A busca por alguns sonhos, como a formação de um "Estados Unidos da África”, tentava compensar o fato de que o continente havia se tornado fragmentado e composto por países pequenos e de potencial econômico limitado. Porém, mais do que isso, a ideia de uma África unida servia para contrabalancear os fortes resquícios do imperialismo que perduravam no continente, como o racismo (especialmente nos regimes segregacionistas na África do Sul e Rodésia, atual Zimbábue), o colonialismo (como no caso da persistência do domínio português sobre Angola, Moçambique e Guiné-Bissau), além das crescentes pressóes impostas pelas superpotências, durante a Guerra Fria.

Para alguns autores, elementos como o racismo e o colonialismo, quando combinados de forma duradoura durante séculos, contribuíram para a construção de uma identidade cultural pan-africana que, diferentemente da maioria dos demais países em desenvolvimento, evoluiu mais como uma expressão de uma identidade negra e africana, do que simplesmente sob uma ótica de integração política ou econômica (MCCARTHY,1995 apud MARINOV, 2014.

Foi sob a luz dessas ideias que, em maio de 1963, os líderes de trinta e três países africanos recém independentes se reuniram na capital da Etiópia, Adis Abeba, para a cerimônia de inauguração da Organização da Unidade Africana (OUA). Na véspera, Kwame Nkrumah, presidente da República de Gana, liderança do movimento de independência do país e um dos principais defensores do Pan-africanismo, declarou:

Somente a partir de uma base continental nós seremos capazes de planejar apropriadamente a utilizaçáo de todos os nossos recursos para o completo desenvolvimento de nosso continente. De que outra maneira nós iremos reter nosso próprio capital e nosso desenvolvimento? De que outra forma nós iremos estabelecer um mercado interno para nossas próprias indús- 
trias? Ao pertencermos a diferentes zonas econômicas, como nós iremos romper as barreiras monetárias e comerciais entre os Estados africanos e como os mais economicamente fortes entre nós serão capazes de ajudar os Estados mais fracos e menos desenvolvidos? (AFRICAN UNION, 1963, tradução nossa). ${ }^{6}$

Nas décadas seguintes, a OUA desempenhou o papel de principal instituição incentivadora do processo de integração, agindo como um fórum de coordenaçáo política - apoiando esforços contra o colonialismo e apartheid mas também de desenvolvimento econômico, promovendo a cooperação entre os países do continente. ${ }^{7}$

No entanto, a partir dos anos 1970, a África se encontrava em um contexto diverso daquele caracterizado pela década de 1960. O otimismo dos anos imediatos aos processos de independência havia dado lugar a uma sucessáo de crises políticas. No plano econômico, a situação da maioria dos países também apresentava problemas. A estratégia de desenvolvimento por meio do modelo de substituição de importaçóes não ofereceu os resultados esperados. Os países da África Subsaariana, durante as décadas de 1970 e início dos anos 1980, continuaram a apresentar uma taxa de crescimento per capta menor do que a média mundial e, inclusive, em relação ao próprio desempenho quando comparado à década anterior. Outros elementos, como corrupção e as crises do petróleo, em 1973 e 1979, contribuíram para piorar o desempenho econômico e aumentar a dívida externa (ODI, 1982).

No campo político, o sonho de uma África próspera e unida parecia ter ficado mais distante à medida em que alguns dos problemas comumente identificados com a realidade política africana tornaram-se mais comuns. Diversas lideranças associadas com o Pan-africanismo foram gradualmente removidas, geralmente com o apoio dos interesses coloniais que tanto buscavam combater. Kwame Nkrumah sofreu um golpe militar em 1966; Patrice Lumumba, do Zaire (atual República Democrática do Congo, RDC), foi deposto e assassinado em 1960; e o imperador Haile Selassie, da Etiópia, foi deposto em 1974.

Ao mesmo tempo, os desafios inerentes à formação de um Estado-nação foram tornando- se evidentes. A Nigéria entrou em uma guerra civil (1967-

\footnotetext{
6 "Only on a continental basis shall we be able to plan the proper utilisation of all our resources for the full development of our continent. How else will we retain our own capital for own development? How else will we establish an internal market for our own industries? By belonging to different economic zones, how will we break down the currency and trading barriers between African states, and how will the economically stronger amongst us be able to assist the weaker and less developed states?" (AFRICAN UNION, 1963).
}

7 A OUA foi substituída pela União Africana (UA) em 09 de julho de 2002. 
1970), após a tentativa de secessão da província de Biafra, assim como Chade (1965-1979) e o Sudão (1955-1972). Além disso, entre julho de 1977 e março de 1978, Somália e a Etiópia travaram uma guerra pela região de Ogaden.

Apesar de todo esse contexto conturbado, alguns importantes acordos de integração regional foram assinados no período. Em abril de 1980, cinquenta países assinaram o chamado Plano de Ação de Lagos, cujo objetivo era estabelecer uma ação conjunta do continente africano nas áreas de desenvolvimento, autossuficiência e integração econômica, bem como promover a diminuição da dependência dos países ocidentais nos mais diferentes setores, como agricultura, indústria, ciência e tecnologia, energia e meio-ambiente.

Havia o reconhecimento de que a situação do continente se encontrava muito aquém do cenário projetado, no entanto, também havia a noção de que o contexto era agravado pela contínua vulnerabilidade da África em relação aos países desenvolvidos. Esse cenário já podia ser percebido desde o parágrafo primeiro do preâmbulo (AFRICAN UNION, 1980, tradução nossa):

O efeito de promessas não cumpridas das estratégias de desenvolvimento global tem sido sentido de forma mais aguda na África do que em qualquer outro continente do mundo. De fato, ao invés de resultar em uma melhora da situação econômica do continente, estratégias sucessivas o fizeram estagnar e tornar-se mais suscetível do que outras regióes às crises econômicas e sociais sofridas pelos países industrializados. ${ }^{8}$

Logo depois, no parágrafo terceiro, diante da percepção de que somente a uniáo entre os povos africanos seria capaz de garantir alguma vantagem frente aos desmandos e à competiçáo por parte dos países de fora do continente, os países africanos declararam: "nós nos comprometemos, individualmente e coletivamente, em nome dos nossos governos e povos, a promover a integração econômica da região africana, com o objetivo de facilitar e reforçar trocas sociais e econômicas"(AFRICAN UNION, 1980, tradução nossa). ${ }^{?}$

Uma das principais consequências do Plano de Ação de Lagos foi a criação, ao longo das décadas de 1980 e 1990, das chamadas Comunidades Econômicas

\footnotetext{
8 "The effect of unfulfilled promises of global development strategies has been more sharply felt in Africa than in the other continents of the world. Indeed, rather than result in an improvement in the economic situation of the continent, successive strategies have made it stagnate and become more susceptible than other regions to the economic and social crises suffered by the industrialised countries" (AFRICAN UNION, 1980).

9 "We commit ourselves, individually and collectively, on behalf of our governments and peoples, to promote the economic integration of the African region in order to facilitate and reinforce social and economic intercourse". (AFRICAN UNION, 1980).
} 
Regionais (CERs), em sua grande maioria mantendo uma organização que tomava por base os agrupamentos geográficos elaborados pelas potências colonizadoras.

Como complemento às CERs, a OUA também deu prosseguimento aos seus esforços de unificação do continente. Em junho de 1991, onze anos após o Plano de Ação de Lagos, os membros da OUA assinaram o tratado de Abuja, na Nigéria, que formalizou as medidas adotadas pelo Plano e estabelecia o projeto para a criação de uma Comunidade Econômica Africana (CEA $)^{10}$. Entre seus objetivos, o ponto que mais se destaca é o apelo dos membros em prol da criação de um Mercado Comum Africano, desenvolvido em estágios e que inicialmente incluiria a criação de uma zona de livre-comércio e a abolição de tarifas alfandegárias, chegando eventualmente à posterior criação de um Banco Central Africano e uma união monetária. Todo esse processo seria construído a partir do fortalecimento das CERs (AFRICAN UNION, 1991).

Ainda assim, o processo de organização das CERs demorou anos para se concretizar. Outros subgrupos específicos foram criados dentro das organizaçóes já existentes, e, de forma geral, cada Estado membro ou CER estabelecia suas próprias datas e parâmetros de implementação de seus objetivos. Outro problema comum eram os casos de sobreposição, com países integrando duas ou até mesmo três CERs simultaneamente. Para Hartzenberg (2011, p.1, tradução própria): "como resultado, os governos africanos concluíram um grande número de acordos de integração regional, vários dos quais têm significativos problemas de sobreposição. Ainda que caracterizados por objetivos ambiciosos, ele tem um péssimo histórico de implementação". ${ }^{11}$

No entanto, como veremos a seguir, apesar desses diversos contratempos e falhas em cumprir uma agenda de implementação, os avanços dos projetos de integração no continente africano não ficaram totalmente estagnados ao longo dos anos.

\section{O Acordo Continental Africano de Livre-Comércio}

Em janeiro de 2012, durante a $18^{\circ}$ Reunião de Chefes de Estado e Governo da União Africana, em Adis Abeba, os líderes africanos concordaram

\footnotetext{
${ }_{10}$ Apesar do Plano de Ação de Lagos (1980) ter formalizado o desejo pela criação de uma Comunidade Econômica Africana (CEA), documentos anteriores, como a Declaração de Kinshasa (1976) e a Declaração de Monróvia (1979) já demonstravam essa ambição.

11 "As a result, African governments have concluded a very large number of regional integration arrangements, several of which have significant membership overlap. While characterized by ambitious targets, they have a dismally poor implementation Record" (HARTZENBERG, 2011, p.1).
} 
em criar uma zona de livre comércio entre os países do continente, até o ano de 2017. O objetivo seria aumentar o comércio entre os países africanos, assim como cumprir uma primeira etapa em direção à criação de um mercado comum no continente. Durante a reunião do ano seguinte, em 2013, os líderes da UA reforçaram o desejo da criação de uma área de livre comércio, durante o lançamento da Agenda 2063 (AFRICAN UNION, 2013).

As negociaçóes efetuadas durante diversas outras reunióes especiais atrasaram o cronograma inicialmente estipulado em mais de um ano, porém, no dia 21 de março de 2018, os países membros da União Africana se reuniram em Kigali, capital de Ruanda, para a 10a Sessão Extraordinária da Assembleia da União Africana (UA) sobre o AfCFTA, para a assinatura de três acordos históricos para a África e um marco para os processos de integração em todo o mundo. $\mathrm{Na}$ ocasião, o então presidente da UA, líder de Ruanda e anfitrião da reunião, Paul Kagame, declarou: "Este é um pacto histórico que está sendo preparado há quase 40 anos e representa um grande avanço para a integração africana e sua união." (AFRICAN UNION, 2018, traduçáo livre). ${ }^{12}$

O primeiro deles, o Protocolo sobre a Livre Circulação de Pessoas, tem como objetivo principal resolver a dificuldade dos africanos em viajar dentro do próprio continente. De acordo com o Africa Visa Openness Index ${ }^{13}$, em 2019, $75 \%$ dos países da África requeriam vistos de cidadãos de outros países africanos. Embora esse número ainda seja alto e a adesão dos países em relação a esse acordo em específico tenha sido baixa (apenas 27 dos 55 países da UA optaram por assiná-lo), o Protocolo foi um passo adiante em direção ao projeto de criação de um Passaporte da União Africana e a facilitação da circulação de pessoas dentro do continente.

Os outros dois acordos - a Declaração de Kigali e o AfCFTA - trataram da criação de uma zona de livre-comércio, com os países membros se comprometendo a eliminar as tarifas de $90 \%$ dos bens, serviços e produtos negociados no continente, dentro dos cinco anos seguintes após o acordo entrar em vigor, promovendo o livre trânsito de pessoas e capitais, facilitando investimentos e tendo, como objetivo final, a meta de estabelecer uma uniâo aduaneira no continente.

De acordo com relatório do Banco Mundial (WORLD BANK, 2020), uma vez que o AfCFTA fosse implementado, os benefícios potenciais para os países e as pessoas do continente seriam enormes e diversos. Até 2035, o acordo

\footnotetext{
12 "This is a historic pact which has been nearly 40 years in the making, and it represents a major advance for African integration and Unity" (AFRICAN UNION, 2018).

13 Disponível em: https://www.visaopenness.org/fileadmin/uploads/afdb/Documents/visa-openness-2019.pdf. Acesso em: 28 de ago. 2020.
} 
possui o potencial de retirar 30 milhóes de africanos da pobreza extrema e outros 68 milhôes da pobreza moderada (aproximadamente $8,1 \%$ da população atual) ${ }^{14}$. O PIB total do continente poderia aumentar em US\$ 212 bilhóes e o crescimento da renda regional chegaria a uma média de 7,0\%. No caso do comércio, o intercâmbio intracontinental poderia crescer $81 \%$, enquanto as trocas com países de fora do continente poderiam subir $19 \%$.

Dentre os 55 países membros da UA, 44 assinaram o AfCFTA durante a reunião de Kigali, em março de 2018 . Em julho do mesmo ano, durante a $31^{\circ}$ Cúpula da União Africana, em Nouakchott, na Mauritânia, cinco outros países assinaram o AfCFTA:Serra Leoa, Namíbia, Lesoto, Essuatíni e África do Sul, cuja posição como potência africana e segunda maior economia do continente representou uma adição importante. Em seguida, em fevereiro de 2019, Guiné Bissau, Zâmbia e Botswana aderiram, seguidos pelo Benin e a Nigéria, em julho daquele mesmo ano.

De fato, o processo de adesão da Nigéria ao AfCFTA merece destaque. Sendo o país mais populoso da África (aproximadamente 202 milhões de habitantes), e a maior economia (com um PIB de US\$410 bilhóes, em 2019) - correspondendo a $18,13 \%$ do PIB do continente - a cautela da Nigéria em assinar o AfCFTA representava uma ausência vital que poderia muito bem comprometer a credibilidade do acordo. Na época, o presidente da Nigéria, Muhammadu Buhari justificou a recusa inicial do país em assinar o AfCFTA, alegando a necessidade de consultar setores domésticos antes de tomar uma decisão.

A questão era particularmente sensível para algumas áreas da economia, como o setor manufatureiro que, temeroso que o acordo acabasse gerando a prática de dumping no país, pedia que o governo realizasse mais estudos sobre seus possíveis impactos. Por outro lado, o medo das consequências advindas da adesão ao acordo convivia com os temores de que a Nigéria, apesar da relevância de sua economia, ficasse isolada dentro do continente. Na época, o presidente da Associação de Fabricantes da Nigeria (MAN, na sigla em inglês), Frank Udemba Jacobs (MAN, 2018), demonstrou esse dilema em uma coletiva de imprensa:

Para evitar dúvidas, nós, novamente, pedimos que o Sr. Presidente não assine o acordo até que as conclusóes de um estudo confiável assim o indique, mas que graciosamente permita que a delegação da nação retome sua participação no processo de negociação APENAS para garantir que o país esteja a par de seus desenvolvimentos. Isto certamente não colocará

\footnotetext{
${ }^{14}$ De acordo com o Banco Mundial, as categorias de pobreza extrema e pobreza moderada referem-se, respectivamente, aos indivíduos que recebem menos de US\$1,50 por dia e menos de US\$ 5,50 ao dia.
} 
em risco ou impedirá a nossa posição caso nós, eventualmente, decidamos que o Acordo não está, definitivamente, a nosso favor. Irá apenas significar que, enquanto mantemos nossos olhos no que se passa, nós podemos continuar com o nosso muito necessário e soberano caminho para determinar se devemos assinar ou não. ${ }^{15}$ (MAN, 2018).

Em meio a dúvidas e debates acerca do tema, em dezembro de 2018, Buhari aprovou a criação um Comitê Nacional de Ação para a Implementação do AfCFTA, com o objetivo de julgar as possíveis consequências - positivas e negativas - do acordo para o país (NIGERIA, 2019). No dia 07 de julho de 2019, após um parecer positivo por parte do comitê, a Nigéria (junto com o Benin) assinaram o AfCFTA durante a abertura da $12^{\circ}$ Sessão Extraordinária da UA sobre o tema, em Niamey, capital do Níger.

No entanto, mesmo com a adesão tardia da Nigéria, o AfCFTA já havia sido consolidado meses antes, quando a Gâmbia se tornou o $22^{\circ}$ membro a ratificar o tratado, o que, pelo artigo $23^{\circ}$ do acordo, tornava os seus dispositivos válidos trinta dias após o depósito do instrumento de ratificação. Assim, no dia 30 de maio de 2019, o AfCFTA entrava em vigor (AFRICAN UNION, 2019).

Por fim, o único país que não assinou o AfCFTA até o momento, foi a Eritreia. Muitas vezes visto como Estado "pária”, o país localizado no leste da África vive uma realidade turbulenta, dentro e fora de suas fronteiras. No plano interno, a Frente Popular para a Democracia e Justiça (FPDJ), controlada pelo presidente Isaias Afewerki, está no poder desde a independência do país, em 1993, após uma guerra de trinta anos contra a Etiópia, sendo seu governo constantemente acusado por violaçóes de direitos humanos e medidas antidemocráticas.

No plano internacional, a Eritreia envolveu-se novamente em mais uma guerra com a Etiópia (1998-2000), além de possuir tensóes fronteiriças com a Somália. Em 2007, o país suspendeu a sua participação na organização regional de países do chifre da África, a Autoridade Intergovernamental para o Desenvolvimento (IGAD, na sigla em inglês) e não foi mais aceita na organização, mesmo quando desejou retornar, em 2011 (WEBER, 2015). No entanto, segundo o Comissário do Comércio e Indústria da UA, Albert Muchanga

\footnotetext{
15 "For the avoidance of doubt, we again request that Mr President should not sign the AfCFTA agreement until the outcome of a credible study so indicate, but graciously allow the nation's team to resume participation in the negotiation processes ONLY to ensure that the country is abreast of developments. This will certainly not jeopardise or constrain the reservation of our assent, should we eventually decide that the Agreement is definitely not in our favour. It will only mean that, whilst keeping our eyes on the goings-on, we can continue with our much needed and sovereign path to determine whether we should sign-on or not" (MAN, 2018).
} 
(2019), a ausência da Eritreia ocorreu devido à falta, na época, de um acordo de paz com a Etiópia. Porém, uma vez que a Cúpula Eritreia-Etiópia, de 2018, selou formalmente a paz entre os dois países, o governo eritreu do presidente Afewerki poderia estar mais disposto a assinar o AfCFTA em um futuro próximo.

\section{Desafios ao Avanço da AfCFTA}

A África possui, simultaneamente, um enorme potencial e grandes dificuldades a serem superadas. O legado do colonialismo gerou efeitos nocivos na política, economia e sociedade africanas, muitos dos quais permaneceram no período posterior às independências nacionais, como a persistência de instituiçôes políticas autoritárias e corruptas, em alguns países, práticas econômicas apenas voltadas para o escoamento da produção para o mercado internacional e uma infraestrutura que não atende às demandas das populaçôes locais.

De maneira geral, muitas dessas dificuldades dizem respeito à própria diversidade africana. O continente africano é o segundo maior do mundo, tanto em extensão territorial quanto em população. Além disso, além de ser também o maior do mundo em número de países (54 Estados reconhecidos pela ONU), em cada um deles podemos encontrar dezenas de idiomas e etnias diferentes, diversos modelos de Estado e governo, assim como de tamanho de economias e distribuição de recursos naturais. Toda essa pluralidade torna a África riquíssima em diversidade cultural, política, econômica e geográfica, mas também torna o seu processo de integração mais complexo e desafiador.

Fatores como a relutância dos governos em ceder parte de sua autonomia em relação às tarifas comerciais; a persistência da violência política no continente; as dificuldades geradas por uma sobreposição de acordos comerciais pré-existentes e, finalmente, as disparidades econômicas entre os países africanos, serão apresentados a seguir.

\section{Relutância dos Governos}

Apesar de representar apenas um passo inicial dentro das etapas de integração econômica entre os países, convencer qualquer governo a abrir mão de medidas tradicionalmente identificadas como sendo parte de prerrogativas nacionais e, em nome de projetos cujos resultados positivos podem demorar anos para apresentarem resultados, pode representar um dilema difícil para os líderes africanos que, como quaisquer outros governantes, têm de levar em consideração a pressão de forças internas sobre as suas decisóes. 
A relutância da Nigéria em assinar o AfCFTA é um exemplo disso. A posição do presidente nigeriano, Muhammadu Buhari, foi cautelosa em relação ao acordo, tendo inicialmente se recusado a assiná-lo devido à pressão contrária dos setores manufatureiros do país. Foi apenas depois de sua reeleição, em fevereiro de 2019, que Buhari concordou em aderir ao acordo.

Se, em um país relativamente democrático como a Nigéria, com eleiçóes regulares e alguma alternância de poder, o compromisso de aderir a um acordo internacional como o AfCFTA pode ser difícil devido aos múltiplos interesses internos da sociedade, em outros casos, como o da Eritreia, o autoritarismo político também pode representar dificuldades e gerar inseguranças. Em novembro de 1994, o governo eritreu divulgou um relatório contendo a análise e os objetivos macroeconômicos do país, que incluíam:

Apoiar regimes internos e externos de liberalizaçáo comercial com limitadas intervençôes, que não contradigam os preceitos do livre comércio. Isso significa, entre outras coisas, liberalizar e simplificar os regimes de licença e reduzir e eliminar barreiras tarifárias e não tarifárias. (ERITREA, 1994, p.32, tradução nossa) ${ }^{16}$

Apesar do relatório defender exatamente a agenda proposta pelo AfCFTA, a política da Eritreia desde a sua independência tem sido errática. Atualmente, o país é dominado por um regime de partido único, autoritário, extremamente militarizado e uma economia baseada em um mercado paralelo, dominado pelo próprio governo e que consequentemente teria pouco interesse em adequar-se à transparência necessária para esse tipo de acordo (REISEN; SABA, 2019). Ao analisarmos o histórico de interação da Eritreia, não só dentro da África Oriental, mas também em todo o continente, os esforços de um governo autoritário para manter o país isolado, tanto politicamente quanto economicamente, oferecem uma hipótese para o porquê do país poder optar por voluntariamente permanecer excluído do AfCFTA. Nas palavras diretas do jornalista, Henry Nzekwe (2019, tradução nossa) "Por que a Eritreia não assinou o acordo da AfCFTA? Basicamente por repressão". ${ }^{17}$

\footnotetext{
16 "The government will foster liberal internal and external trade regimes with limited interventions that would not contradict the tenets of free trade. This will mean, among other things, liberalizing and simplifying the licesing regime and reducing and eliminating tariff and non-tariff barriers". (ERITREA, 1994, p.32).

17 “Why Eritrea has not signed the AfCFTA agreement? It's mostly down to repression”. (NZEKWE, 2019).
} 
A Eritreia pode representar um caso extremo dentro da África, no entanto, o seu exemplo serve como uma amostra das dificuldades que um acordo de liberalização de comércio pode encontrar em regimes politicamente pouco liberais em outras partes do continente e do quáo instável uma posição adotada dentro de um regime autoritário pode vir a ser.

\section{Violência Política}

Outro grande problema é a persistência de conflitos armados e golpes de Estado no continente. Segundo o relatório Annual Risk of Coup Report, 2019, desde 1950 até 2018, a África Subsaariana foi palco de um total de 186 golpes de Estado ( $71 \%$ de todos os golpes de Estado ocorridos no mundo), 50 deles ocorridos depois do ano 2000 (OEF RESEARCH, 2019).

Desde entâo, outros golpes (bem-sucedidos ou fracassados), como no Gabão (janeiro de 2019), Sudão (abril de 2019), Etiópia (junho de 2019) e recentemente no Mali (agosto de 2020), demonstraram que a transmissão de poder dentro de muitos países do continente ainda ocorre de forma violenta. Isso sem contar a persistência de conflitos civis, como na Líbia, Somália e Sudão do Sul, ou a presença de grupos extremistas, como na Nigéria, Uganda e RDC.

Esse cenário de intensa instabilidade - típico de países onde a atividade política é vista como um jogo do tipo "o vencedor leva tudo" - também gera uma insegurança institucional capaz de prejudicar acordos previamente estabelecidos, inclusive compromissos referentes ao AfCFTA. A figura 1, abaixo, apresenta a atual situação de violência na África. 
Figura 1 - Conflitos e Instabilidades Políticas na África Subsaariana (2020)

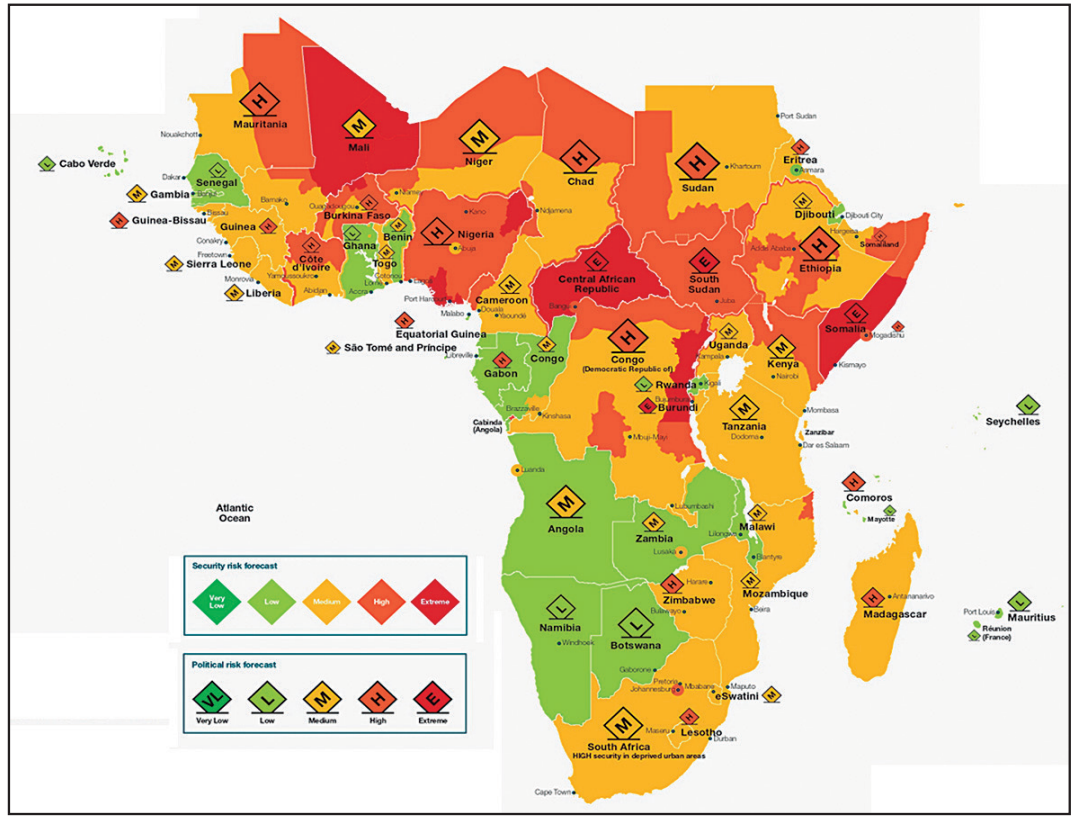

Fonte: Control Risks ${ }^{18}$.

\section{Sobreposição das agendas das CERs}

Um outro desafio típico do continente africano está na questão das Comunidades Econômicas Regionais (CERs). Anteriormente, vimos como maioria das CERs foram constituídas durante os anos 1980 e 1990, como parte da estratégia de promover a uniáo continental dos países africanos, primeiro, por meio da seleção e integração dos mais de cinquenta países africanos em algumas poucas CERs, para depois - quando o processo estivesse em um estágio mais avançado -, prosseguir em direção à união continental.

Assim, em um curto período de tempo foram criadas oito principais Comunidades Econômicas Regionais, cada uma com uma agenda, objetivos e processos decisórios distintos uma das outras: a Comunidade dos Estados Sahel-saarianos (CEN-SAD), em 1998; o Mercado Comum da África Oriental e Austral (COMESA), em 1994; a Comunidade da África Oriental (EAC),

\footnotetext{
${ }^{18}$ Disponível em: https://www.controlrisks.com/-/media/corporate/files/riskmap/maps/riskmap-2020-map-regionsafrica-a3-hr.pdf. Acesso em: 28 de ago. 2020.
} 
em 1991; a Comunidade Econômica dos Estados da África Central (ECCAS/ CEEAC), em 1985; Comunidade Econômica dos Estados da África Ocidental (CEDEAO), em 1975; a União Autoridade Intergovernamental para o Desenvolvimento (IGAD), em 1986; a Comunidade para o Desenvolvimento da África Austral (SADC), em 1980; e a União Árabe do Magrebe (UAM), em 1989.

Como já vimos, apesar das vantagens envolvidas em participar de um bloco regional, a medida também exige de um governo a decisão de se adequar às práticas e ritmos de trabalho do grupo. No entanto, diversos países optaram por juntar-se a mais de uma CER (em alguns casos, até três ou quatro) como uma estratégia para aumentar o seu poder de decisão dentro dos blocos e optando pelo cronograma de trabalhos ou processo decisório das Comunidades que melhor atenderem aos seus objetivos individuais em determinado momento. Como consequência disso, de acordo com relatório da Comissão Econômica das Naçóes Unidas para a África, 95\% dos membros de uma CER também são membros de outra comunidade, com países como o Quênia e o Burundi participando de quatro CERs diferentes e a DRC, de cinco (AFRICAN UNION, 2006).

O resultado prático disso foi prejudicial aos avanços do processo de integração do continente. O baixo nível de cumprimento dos programas de integração, a implementação de agendas conflituosas, pagamentos e contribuiçóes insuficientes e até pouco comparecimento às reunióes, podem ser citados como consequências negativas da transformação das CERs em meros instrumentos de políticas nacionais ao invés de mecanismos de integração regional. A figura 2, logo abaixo, demonstra as diversas CERs e os países que fazem parte delas. 
Figura 2 - Diagrama com os países africanos e as CERs às quais eles fazem parte

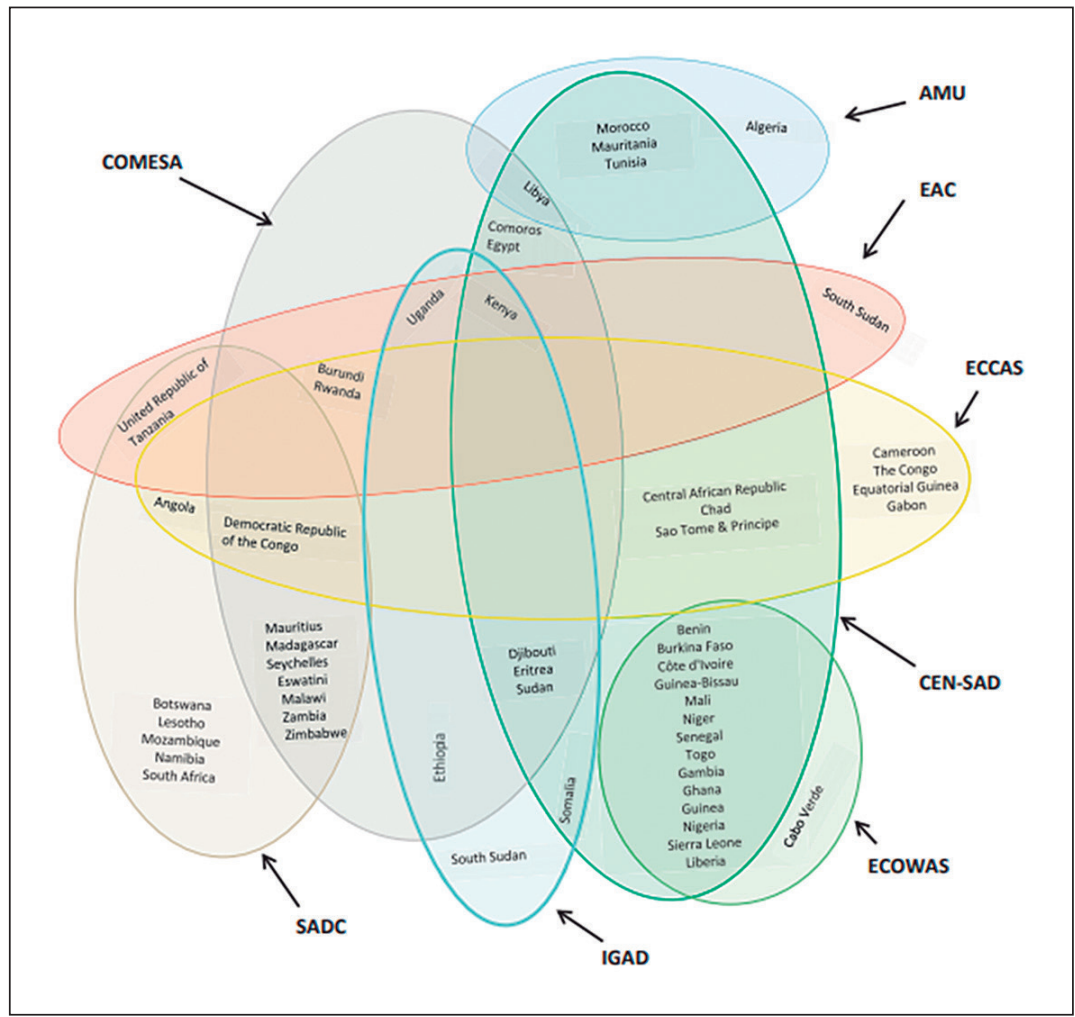

Fonte: UNCTAD (2019a, p.8).

\section{Disparidades Econômicas}

A pobreza e a desigualdade ainda são elementos que assolam o continente africano. Países como a República Centro-Africana, Burundi e a RDC sempre estão inclusos nas listas dos dez países mais pobres do mundo. De fato, dos 47 Estados considerados Países Menos Desenvolvidos (PMD) pela Conferência das Naçôes Unidas para Comércio e Desenvolvimento (UNCTAD, na sigla em inglês), em 2019, 33 são africanos. ${ }^{19}$

Dessa forma, a desigualdade econômica na África representa um desafio extra à implementação do AfCFTA. Uma potência econômica, como a Nigéria,

\footnotetext{
${ }^{19}$ Segundo a UNCTAD, os países são: Libéria, Madagascar, Malawi, Mali, Mauritânia, Moçambique, Níger, Ruanda, São Tomé e Príncipe, Senegal, Serra Leoa, Somália, Sudão do Sul, Sudão, Togo, Uganda, Tanzânia e Zâmbia (UNCTAD, 2019c).
} 
tem que adequar ao ritmo de um vizinho pequeno, como o Benin, enquanto uma economia extremamente dependente de um só recurso, como a Angola (no caso, o petróleo) tem que se adaptar em relação às importaçôes de países com uma economia mais diversificada, como a da África do Sul.

Além disso, a maioria dos países ainda possui economias altamente dependentes da exportação de matérias-primas, inseridas de maneira periférica dentro das cadeias de suprimento global. Essa realidade se reflete diretamente nos números das trocas comerciais entre os países do continente. Segundo o relatório Economic Development in Africa (UNCTAD, 2019b), em 2017 as exportaçóes dos países africanos para outros destinos dentro do continente somaram 16.6\% do total. A taxa representa um grande avanço quando levamos em consideração que ela era de apenas $9,0 \%$ no ano 2000, porém, ela ainda permanece baixa, quando comparada a de outros continentes ${ }^{20}$. Se levarmos em consideração o fluxo comercial total (soma dos valores das importaçóes e exportaçóes), o número é menor ainda, chegando a apenas $2,0 \%$.

A desigualdade entre os países africanos não é a única disparidade a ser superada. No intervalo entre 2000 e 2017, 70\% dos produtos importados pela África consistiam em manufaturados, maquinário e produtos químicos. Ao mesmo tempo, 60\% das exportaçóes africanas para fora do continente foram de matérias-primas, como petróleo e minerais (ABREGO et al., 2020). Os números acima revelam um problema constante dos países africanos em ter grande parte de suas receitas atreladas à exportação de commodities e todas as consequências relacionadas à dependência de produtos com valores instáveis e cuja queda no mercado internacional pode ser um fator desestabilizador para as economias do continente.

\section{Considerações Finais}

A integração do continente africano é um sonho compartilhado por diversos intelectuais e personalidades políticas desde o período colonial e que se estende até os dias de hoje. Entretanto, à medida em que os africanos foram conquistando sua independência, ficou claro que a realidade imposta à África seria a de um continente fragmentado em pequenos países, muito diferentes entre si em relação aos seus territórios, populaçôes e tamanho das economias.

Ironicamente, o surgimento dos Estados africanos, em sua maioria, entre as décadas de 1950 e 1960, deu-se em uma época em que, na Europa (principal

\footnotetext{
${ }^{20}$ Em 2017, os países europeus exportaram 68,1\% de seus produtos para destinos dentro do próprio continente; na Ásia, o valor foi de 59.4\%, na América, $55,0 \%$ e na Oceania, 7,0\%.
} 
modelo para a construção dos Estados africanos), o conceito de soberania perdia parte de sua condiçáo absoluta e cedia espaço às ideias e práticas que tornariam possível a formação da União Europeia, algumas décadas depois.

A passagem do tempo, marcado pelas dificuldades inerentes ao desafio de se construir Estados nações - a partir de indivíduos e territórios onde a tradicional noção europeia de Estados ou nação não existiam - logo cobraram seu preço. Atualmente, a África tem que lidar com tragédias econômicas e sociais, violência política e interferências estrangeiras, resultado do difícil processo de formação de Estados com antecedentes coloniais.

Apesar disso, quando levamos em consideração as complexidades do cenário político, econômico e histórico da África, a criação de uma área de livre comércio, de dimensóes continentais e que engloba cinquenta e quatro países diferentes, como o AfCFTA, representa um marco não só para os processos de integração na África, mas também em todo o mundo.

Ainda assim, é preciso olhar para o AfCFTA com alguma cautela. Os mesmos elementos que dificultam e tornam o acordo um feito táo notável para a política de integração são os mesmos que podem impedi-lo de progredir. Quando lembramos que o estabelecimento de uma área de livre comércio na África representa apenas um primeiro passo dentro dos compromissos assumidos pelos países, o final parece distante e, provavelmente, terá seu avanço marcado por contratempos.

\section{REFERÊNCIAS}

ABREGO, L. et al. The African Continental Free Trade Area: Potential Economic Impact and Challenges. Washington: IMF, 2020. Disponível em: https://www.imf.org/ en/Publications/Staff-Discussion-Notes/Issues/2020/05/13/The-African-ContinentalFree-Trade-Area-Potential-Economic-Impact-and-Challenges-46235\#:-:text=Once\% 20 fully $\% 20$ implemented $\% 2$ C $\% 20$ the $\% 20$ AfCFTA,of $\% 20$ about $\% 20$ US $\% 242.2 \%$ 20 trillion. \& text $=$ In $\% 20$ addition $\% 20$ to $\% 20$ increased $\% 20$ trade,economic $\% 20$ benefits\%20for\%20African\%20countries. Acesso em: 11 de set. 2020.

AFRICAN UNION. Agreement Establishing The African Continental Free Trade Area. 2019. Disponível em: https://au.int/sites/default/files/treaties/36437-treatyconsolidated_text_on_cfta_-_en.pdf. Acesso em: 30 ago. 2019.

AFRICAN UNION. Rwanda to Host the Extraordinary Summit on the AfCFTA: Directorate of Information and Communication. 2018. Disponível: https://au.int/ 
sites/default/files/newsevents/mediaadvisories/33975-ma-media_advisory_rwanda_ to_host_extraordinary_summit_on_the_cfta.pdf. Acesso em: 29 ago. 2020.

AFRICAN UNION. Agenda 2063: The Africa We Want. 2013. Disponível em: https://www.un.org/en/africa/osaa/pdf/au/agenda2063-first10yearimplementation. pdf. Acesso em: 11 set. 2020.

AFRICAN UNION. Assessing Regional Integration in Africa II: Rationalizing Regional Economic Communities. Addis Ababa: Economic Commission for Africa, 2006.

AFRICAN UNION. Treaty Establishing the African Economic Community. 1991. Disponível em: https://www.wipo.int/edocs/lexdocs/treaties/en/aec/trt_aec.pdf. Acesso em: 28 ago. 2020.

AFRICAN UNION. Lagos plan of action for the economic development of Africa 1980-2000. Addis Ababa, 1980. Disponível em: https://www.resakss.org/sites/ default/files/OAU\%201980\%20Lagos\%20Plan\%20of\%20Action\%20for\%20the\%20 Economic\%20Development\%20of\%20Africa.pdf. Acesso em: 28 de ago. 2020.

AFRICAN UNION. His Excellency Kwame Nkrumah: President of the Republic of Ghana. In: AFRICAN UNION. Speeches \& Statements made at the first Organization of African Unity (O.A.U.) Summit. 1963. Disponível em: https:// au.int/sites/default/files/speeches/38523-sp-oau_summit_may_1963_speeches.pdf. Acesso em: 23 ago. 2020.

ERITREA. Macro-Policy. 1994. Available at: http://www.eritreadigest.com/ wp-content/uploads/2018/03/Eritrea-macro-policy.pdf. Access on: 11 Sept. 2020.

FUNDO MONETÁRIO INTERNACIONAL. Real GDP growth. 2019. Disponível em: https://www.imf.org/external/datamapper/NGDP_RPCH@WEO/ ADVEC/WEOWORLD/OEMDC/AFQ. Acesso em: 26 de ago. 2020.

HARTZENBERG, T. Regional Integration in Africa. Staff Working Paper, Geneva, n.ERSD-2011-14, 2011. Available at: https://www.econstor.eu/bitstream/ 10419/57595/1/669412368.pdf. Access on: 11 Feb. 2021.

HURREL, A. Explaining the Resurgence of Regionalism in World Politics. Review of International Studies, Cambridge, v.21, n.4, p. 331-358, 1995.

MANSFIELD, E. D; SOLINGEN, E. 'Regionalism'. Annual Review of Political Science, Palo Alto, v.13, n.1, p.145-63, 2010.

MANUFACTURERS ASSOCIATION OF NIGERIA [MAN]. Press Release On AfCFTA. Ikeja, 2018. Available at: https://www.manufacturersnigeria.org/Press Release?Pid=9. Access on: 30 Aug. 2020. 
MARINOV, E. The History of African Integration: a Gradual Shift from Political to Economic Goals. Journal of Global Economic, Brussels, v.6, n.4, p.74-86, 2014.

MARTIN, G. African Political Thought. New York: Palgrave Macmillan, 2012.

MORAVCSIK, A. The Choice for Europe Social Purpose \& State Power From Messina to Maastricht. New York: Cornell University, 1998.

MOREIRA, E. Portuguese Colonial Policy. Africa: Journal of the International African Institute, Cambridge, v.17, n.3, p.181-191, 1947.

MUCHANGA, A. Nigeria signs African free trade area agreement. BBC News, 2019. Available at: https://www.bbc.com/news/world-africa-48899701. Access on: 3 Aug. 2020 .

MWAPACHU, J. EAC: past, present and future. Official Publication of the East African Community. 2010. Available at: http://firstforum.org/Publishing/Specialist PublishingDetail.aspx?SpecialistPublicationId=24. Access on: 27 Aug. 2020.

NIGERIA. AfCFTA: President Buhari Approves Establishment of National Action Committee (NAC). 2019. Available at: https://statehouse.gov.ng/news/afcftapresident-buhari-approves-establishment-of-national-action-committee-nac/. Access on: 30 Aug. 2018.

NZEKWE, H. 54 Of 55 African Countries Have Signed The New Free Trade Agreement: Here's Why Eritrea Refuses To Okay The Deal. 2019. Available at: https://weetracker.com/2019/07/08/eritrea-refuses-to-sign-new-free-trade-agreement/. Access on: 30 Aug. 2020.

OEF RESEARCH. Annual Risk of Coup Report. 2019. Available at: https:// oefresearch.org/sites/default/files/documents/publications/Risk_of_Coup_Report_2019. pdf. Access on: 10 Sept. 2020.

OVERSEAS DEVELOPMENT INSTITUTE [ODI]. Africa's Economic Crisis. Briefing Paper, London, n.2, Sept. 1982.

RAVENHILL, J. Regional Integration in Africa: Theory and Practice. In: LEVINE, D. H.; NAGAR, D. (ed.). Region-Building in Africa: Political and Economic Challenges. New York: Palgrave Macmillan, 2016. p.37-52.

REISEN, M.; SABA, M. Sons of Isaias': Slavery and Indefinite National Service in Eritrea. In: REISEN, M.; SABA, M. Mobile Africa: Human Trafficking and the Digital Divide. Bamenda: Langaa Research \& Publishing, 2019. p.115-158.

SOUTHERN AFRICA CUSTOMS UNION [SACU]. History of SACU. Available at: http://www.sacu.int/show.php?id=394. Access on: 26 Aug. 2020. 
UNCTAD. Key Statistics and Trends in Regional Trade in Africa. New York, 2019a. Available at: https://unctad.org/en/PublicationsLibrary/ditctab2019d3_en.pdf. Access on: 11 Sept. 2020.

UNCTAD. Economic Development in Africa Report. New York, 2019b. Available at: https://unctad.org/en/PublicationsLibrary/aldcafrica2019_en.pdf. Access on: 11 Sept. 2020.

UNCTAD. UN list of Least Developed Countries. New York, 2019c. Available at: https://unctad.org/en/pages/aldc/Least\%20Developed\%20Countries/UN-list-ofLeast-Developed-Countries.aspx. Access on: 11 Sept. 2020.

WEBER, A. Eritrea: Paths Out of Isolation. SWP Comment, Berlin, 2015/C 37, July 2015. Available at: https://www.swp-berlin.org/fileadmin/contents/products/ comments/2015C37_web.pdf. Access on: 11 Sept. 2020.

WORLD BANK. The African Continental Free Trade Area: Economic and Distributional Effects. Washington: World Bank Group, 2020. Available at: https:// openknowledge.worldbank.org/bitstream/handle/10986/34139/9781464815591. pdf. Access on: 11 Sept. 2020.

Recebido em: 13 de setembro de 2020

Aprovado em: 15 de outubro de 2020 